\title{
Characterization of Nanoemulsion Prepared from Self-emulsifying Rifampicin and its Antibacterial Effect on Staphylococcus aureus and Stap. epidermidis Isolated from Acne
}

\author{
Kohinur Begum¹, Amit Sarker², Israt J ahan Shimu², \\ Md. Mazharul Islam Chowdhury ${ }^{1}$ and Reza-ul J alil ${ }^{3}$ \\ ${ }^{1}$ Department of Pharmacy, ASA University Bangladesh, ASA Tower, Shyamoli, Dhaka 1207, Bangladesh \\ ${ }^{2}$ Department of Pharmacy, Primeasia University, Banani, Dhaka 1213, Bangladesh \\ ${ }^{3}$ Department of Pharmaceutical Technology, Faculty of Pharmacy, University of Dhaka, Dhaka1000, \\ Bangladesh
}

Received: January 04, 2016; Accepted: January 24, 2016; Published (web): January 31, 2016

\begin{abstract}
In this study, three different self emulsifying drug delivery systems of rifampicin (SEDD-R) were made using oleic acid and different surfactants such as Tween 80, Chremophor RH 40 and Chremophor EL designated as RN-TW, RN-CRH and RN- CEL. These self-emulsifying systems were converted to rifampicin nanoemulsion by adding water under sonication. The resulting particle sizes were found to be $192.7 \mathrm{~nm}, 183.4 \mathrm{~nm}$ and $179.2 \mathrm{~nm}$ for RN- CEL, RN-CRH and RN-TW, respectively using Zetasizer. Drug content, entrapment efficiency, in vitro drug release and $\mathrm{pH}$ stability tests was performed. Drug content and entrapment efficiency for RNTW, RN-CRH and RN- CEL were found as $0.9945 \%$ \& $0.9835 \%, 0.9720 \% \& 84.31 \%$ and $74.58 \%$ \& $56.89 \%$, respectively. The release of drug from RN-TW, RN-CRH and RN-CEL occurred for 450-330- and 240- minutes, respectively. The $\mathrm{pH}$ stability study demonstrated that all formulations retained maximum drug at $\mathrm{pH} 5.8$. Antibacterial effect of the preparations was evaluated against $S$. epidermidis and $S$. aureus isolated from acne and showed effective results.
\end{abstract}

Key words: Rifampicin nanoemulsion, entrapment efficiency, in vitro drug release, $\mathrm{pH}$ stability

\section{INTRODUCTION}

Nanoemulsions are isotropic, thermodynamically stable, transparent or translucent dispersions of oil and water stabilized by an interfacial film of surfactant molecules having the droplet size 20-500 $\mathrm{nm} .{ }^{1}$ Selection of an appropriate oily phase is very important as it influences the selection of other ingredients of nanoemulsions, mainly in case of $\mathrm{o} / \mathrm{w}$ nanoemulsions which also helps to achieve maximum drug loading in the nanoemulsions. ${ }^{2}$ However, aqueous phase, $\mathrm{pH}$ and ionic content of aqueous

Correspondence to: Kohinur Begum

Cell: +8801713-080285; E-mail: kohinur025@yahoo.com

Dhaka Univ. J. Pharm. Sci. 14(2): 171-177, 2015 (December) phase also influence stability and droplet size of nanoemulsions. ${ }^{3}$ Nanoemulsions are used to deliver drugs to the patients via several routes, but the topical application of nanoemulsions is given special interest. $^{4-6}$ Nanoemulsions improve the transdermal delivery of several drugs over the conventional topical preparations of emulsions and gels. ${ }^{7}$ Acne primarily affects the face, chest and back because these areas contain the highest concentration pilosebaceous glands. ${ }^{8}$ It is the most common skin disorder in the world with prevalence about $70-87 \%$ and moderate to severe acne affects around $20 \%$ of young people. ${ }^{9,10}$ Staphylococcus epidermidis and Staph. aureus is the causative agent for acne. ${ }^{11-13}$ 
Bacterial resistance to conventional antibiotics such as clindamycin, erythromycin and tetracycline have been reported. ${ }^{14}$ Rifampicin and combination of rifampicin with other antibiotics were found to be the most effective antibiotic for treatment of acne vulgaris. ${ }^{15-17}$ In this study, three different self emulsifying drug delivery systems of rifampicin (SEDD-R) were made using organic acid and different surfactants for topical delivery of drug at the target sites on skin for the treatment of acne.

\section{MATERIALS AND METHODS}

Materials. Rifampicin was procured from Cipla (India). Oleic Acid, Tween 80, Cremophor RH 40,
Cremophor EL), methanol, n-propanol and EDTA were procured from Merck (Germany). All chemicals were of analytical grade. Instrument including analytical balance (Boeco, Germany), Ultra sonic bath (Sonoswiss, Switzerland), Zetarsizer Ver 7.01 (Marlvern UK), Ultraviolet spectrophotometer (Shimadzu, Japan), microcentrifuge machine (M-244, Boeco, Germany) were utilized.

Formulation and preparation of rifampicin nanoemulsion. Three rifampicin nanoemulsion products were formulated and designated as RN-TW, $\mathrm{RN}-\mathrm{CRH}$ and RN-CEL. Ingredients and amounts are given in table 1 .

Table 1. Formulation of rifampicin nanoemulsions.

\begin{tabular}{lccc}
\hline & RN-TW & RN-CRH & RN-CEL \\
\cline { 2 - 4 } Ingredients & Weight in $\mathrm{g}$ & Weight in & Weight in $\mathrm{g}$ \\
\hline Rifampicin & 1.0 & 1.0 & 1.0 \\
Oleic Acid & 5.0 & 5.0 & 5.0 \\
Tween 80 & 40.0 & - & - \\
Cremophor RH 40 & - & 40.0 & - \\
Cremophor EL & - & - & 40.0 \\
Distilled Water & 54.0 & 54.0 & 54.0 \\
Total & 100 & 100 & 100 \\
\hline
\end{tabular}

Preparation RN-TW, RN-CRH and RN-CEL. Preparation of RN-TW was done according to the sonication method with some modification. ${ }^{18}$ For this $1.0 \mathrm{gm}$ of rifampicin was dissolved in $5 \mathrm{gm}$ of oleic acid (oil phase) in $20 \mathrm{ml}$ screw cap glass vial and sonicated at $70^{\circ} \mathrm{C}$ to make a clear solution. Tween 80 (40 gm) was taken in $100 \mathrm{ml}$ glass bottle and heated up to $70^{\circ} \mathrm{C}$ with sonication. Then rifampicin solution in oleic acid was added into Tween 80 in $100 \mathrm{ml}$ glass bottle. On the other hand, $54 \mathrm{~g}$ of water was taken in $100 \mathrm{ml}$ glass bottle and heated at $70^{\circ} \mathrm{C}$ in heating bath. This hot water was slowly added to previously prepared mixture containing rifampicin, oleic acid and Tween 80 with occasional shaking with a vortex. Cloudy nanoemulsion was formed. Then namoemulsion preparation was cooled at room temperature. Same procedures were followed for RN$\mathrm{CRH}$ and $\mathrm{RN}-\mathrm{CEL}$ nanoemulsion preparation (Table 1).
Determination of nanoemulsions. Drop dilution test method was used to determine the type of nanoemulsion. $1 \mathrm{ml}$ sample from each formulation was taken into three different test tubes and equivalent amount of distilled water was added to the test tubes. Then miscibility was observed visually.

Determination of droplet size. $250 \mu \mathrm{l}$ of nanoemulsion was added to $300 \mathrm{ml}$ of distilled water in a $500 \mathrm{ml}$ beaker. A glass rod was used to induce gentle agitation in the mixture. The average droplet size of the nanoemulsions were determined by dynamic light scattering using Zetasizer (Malvern Instruments, Worcestershire, UK) which measures the Brownian motion of the droplet and its relation to the droplet size based on the principle that larger droplets have slower motion.

Determination of drug content. A calibration curve was plotted using the absorbance data against drug concentration. $10 \mathrm{mg}$ rifampicin was taken in $100 \mathrm{ml}$ volumetric flask and methanol was added up 
to the mark to obtain concentration of $100 \mathrm{mg} / \mathrm{l}$. Dilution was made to obtain solutions of 5 different concentrations $(10 \mathrm{mg} / \mathrm{l}, 20 \mathrm{mg} / \mathrm{l}, 30 \mathrm{mg} / \mathrm{l}, 40 \mathrm{mg} / \mathrm{l}$ and $50 \mathrm{mg} / \mathrm{l})$. The absorbance of each solution was measured at $475 \mathrm{~nm}$ using ultraviolet spectrophotometer and standard curve (Figure 1) was constructed. The calibration curve was used to estimate drug content of rifampicin nanoemulsions (RN-TW, RN-CRH and RN-CEL).

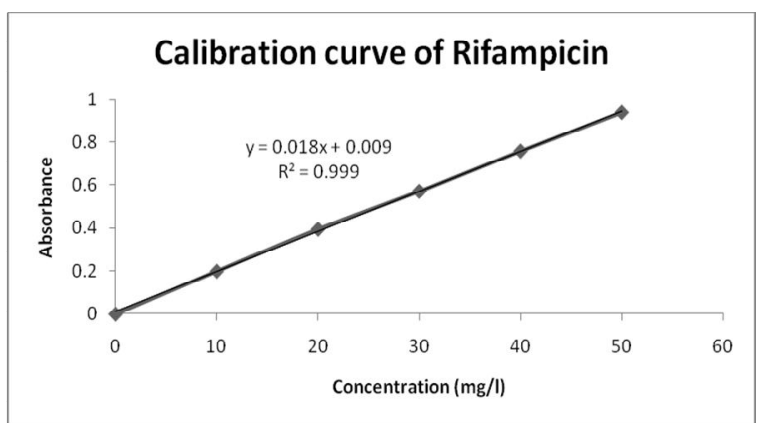

Figure 1. Calibration curve of rifampicin.

Determination of entrapment efficiency. Nanoemulsions containing drug were separated from unentrapped drug by centrifugation at $14000 \mathrm{rpm}$ for 30 minutes and decanted fluid was separated from precipitation. The entrapped drug $(1 \mathrm{ml})$ was disrupted using $3 \mathrm{ml} 50 \%$ propanol for 5 minutes which was analyzed spectrophotometrically for drug content at $475 \mathrm{~nm}$ to calculate the concentration of entrapped drug against $50 \%$ propanol as blank. Percentage of entrapped drug was calculated by applying equation (1). ${ }^{19}$

$\%$ of entrapment $=\mathrm{Ae} \times 100 / \mathrm{Ai}$

Where, Ae is the amount of entrapped drug and $\mathrm{Ai}$ is the initial amount of drug in oil phase.

Determination in vitro drug release. The release of drug from nanoemulsion formulations was determined by dialysis method. ${ }^{19}$ After separating the unentrapped drug, nanoemulsions particles were pipetted into dialysis bag (Visking, DTVO3500). This was placed in $100 \mathrm{ml}$ of phosphate buffer $\mathrm{pH} 7.4$ and kept with constant agitation with magnetic stirrer maintained at $37^{\circ} \mathrm{C} .2 \mathrm{ml}$ sample was withdrawn every 30 minutes and the same volume of buffer was replaced. Then samples were assayed spectrophotometrically at $475 \mathrm{~nm}$ using buffer medium as blank. The release was compared with pure drug solution.

pH stability test. $1 \mathrm{mg}$ entrapped nanoemulsion in $5 \mathrm{ml}$ of phosphate buffer (pH 5.8, 7.00, 8.00) was kept in screw cap test tube for 2 hours at $25{ }^{\circ} \mathrm{C}$ and the samples were withdrawn. Samples were analyzed spectrophotometrically at $475 \mathrm{~nm} .{ }^{19}$

Antibiotic sensitivity test. Antibiotic sensitivity test was performed by cup diffusion using Mueller Hinton agar plates. Bacterial strains such as $S$. epidermidis and $S$. aureus were obtained from laboratory stock which was identified in our previous study. ${ }^{20} \quad 50 \mu \mathrm{g} / \quad 100 \quad \mu \mathrm{l}$ of rifampicin and nanoemulsion preparations (RN-TW, RN-CRH, and $\mathrm{RN}-\mathrm{CEL}$ ) were applied in different cup. The plates were incubated at $37{ }^{\circ} \mathrm{C}$ for 24 hours. Diameter of zone of inhibition was recorded in millimeters and the average diameter of zone of inhibition was taken from duplicate test to determine its sensitivity. ${ }^{21}$

\section{RESULTS AND DISCUSSION}

Nanoemulsion type. Each test tube was visually observed after shaking. Water was mixed well and no phase separation could be observed for each test tube which suggested that the outer layer was water indicating formulations belonged to $\mathrm{o} / \mathrm{w}$ type emulsion.

Droplet size. Droplet size was analyzed by using Zetarsizer and droplet size of different nanoemulsions were found as $192.7 \mathrm{~nm}, 183.4 \mathrm{~nm}$ and $179.2 \mathrm{~nm}$ for RN- CEL, RN-CRH and RN-TW, respectively (Figure 2, Table 2). Droplet size of all formulations was within the range and variation occurred due to different composition of each formulation.

Table 2. Droplet size of rifampicin nanoemulsions.

\begin{tabular}{lc}
\hline Formulation codes & Average droplet size $(\mathrm{nm})$ \\
\hline RN-CEL & 192.7 \\
RN-CRH & 183.4 \\
RN-TW & 179.2 \\
\hline
\end{tabular}




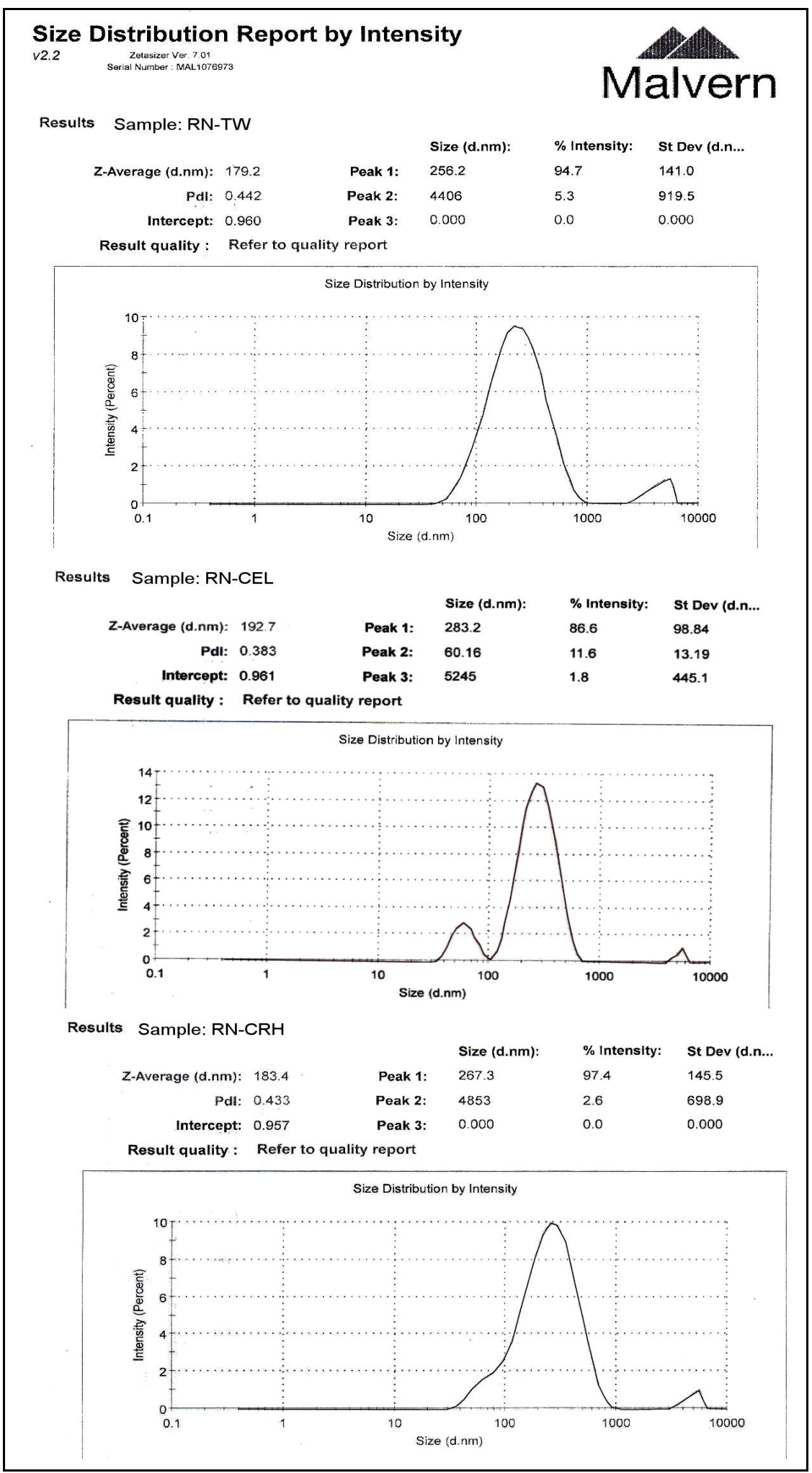

Figure 2. Zetasizer plot of nanoemulsion droplet sizes of RN-TW, RN-CEL and RN-CRH formulaitons. 
Drug content. Drug content of each formulation was calculated by using standard curve. Drug contents of RN-TW, RN-CRH and RN- CEL were found as $0.9945 \%, 0.9835 \%$ and $0.9720 \%$, respectively. Drug content for all nanoemulsions was found to be satisfactory (Table 3).

Table 3. Drug content of rifampicin in formulations.

\begin{tabular}{lcc}
\hline $\begin{array}{l}\text { Formulations } \\
\text { code }\end{array}$ & $\begin{array}{c}\text { Concentration } \\
(\mathrm{mg} / \mathrm{l})\end{array}$ & $\begin{array}{c}\text { Drug content } \\
(\% \mathrm{w} / \mathrm{w})\end{array}$ \\
\hline RN-CEL & 19.44 & 0.9720 \\
RN-CRH & 19.67 & 0.9835 \\
RN-TW & 19.89 & 0.9945 \\
\hline
\end{tabular}

Entrapment efficiency. Results of entrapment efficiency showed that, the highest entrapment efficiency was found in Tween-80 surfactant containing nanoemulsions $(84.31 \%)$, then Cremophor RH $40(74.58 \%)$ and moderately entrapped when Cremophor EL (56.89\%) was used (Figure 3). Becher $^{22}$ reported that, $\mathrm{o} / \mathrm{w}$ nanoemulsion was required emulsifying agents having HLB value ranging from 8-18 and higher HLB values offered greater entrapment clarity efficiency. Skin penetration as well as skin retention of drug depend on percentage of entrapped drugs in nanoemulsion system. $^{23}$ Nanoemulsion has been explored extensively for topical application to enhance skin penetration as well as to improve skin retention of drugs.

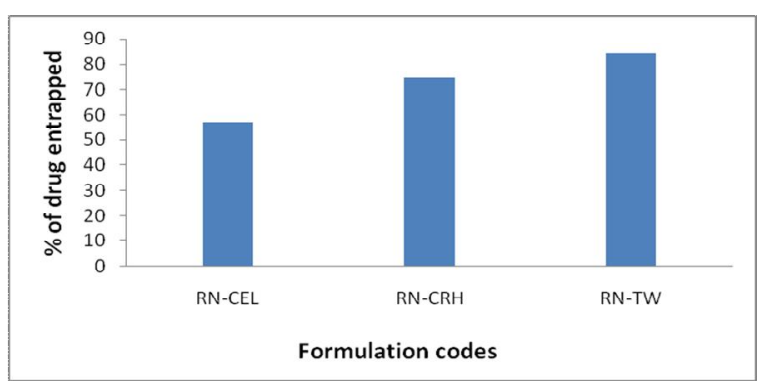

Figure 3. Entrapment efficiency of rifampicin nanoemulsions.

In vitro drug release. Results of in vitro drug release revealed that Tween 80 surfactant containing nanoemulsion (RN-TW) was released drugs for longer time (450 minutes) at a controlled rate $(0.33$ $\mathrm{mg} / \mathrm{l}$ per 30 minutes) due to high entrapment efficiency of drugs as compared to other formulations. It was found that $3.3 \mathrm{mg} / \mathrm{l}$ standard drug released within 90 minutes whereas RN-CEL, RN-CRH and RN-TW required 150, 240 and 360, minutes respectively. Finally, all standard drugs were released within 150 minutes but equivalent amount of drug in RN-CRH, RN-TW could be released in 300 minutes and 450 minutes, respectively (Figure 4). From this study, it was suggested that Tween 80 surfactant containing nanoemulsions offered better extended release of drugs at controlled rate when compared with other formulations.

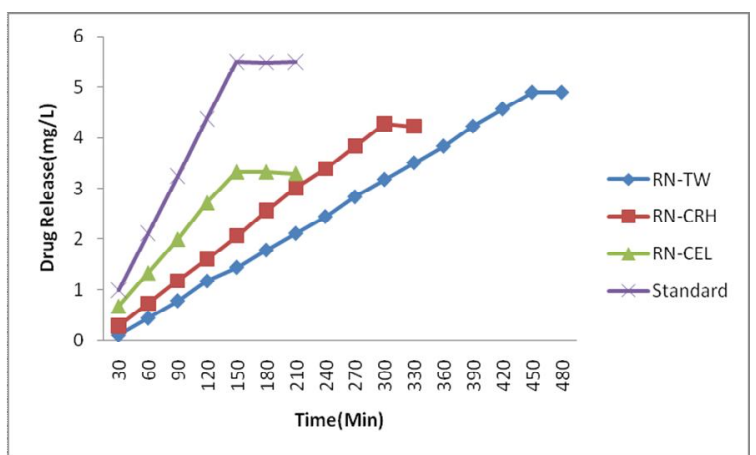

Figure 4. In vitro drug release of rifampicin standard and different rifampicin nanoemulsions.

pH stability test. In this study, all preparations retained maximum drugs at $\mathrm{pH} 5.8$ which indicated that formulations were stabled at $\mathrm{pH} 5.8$ (Figure 5). Barry $^{24}$ reported that, delivery of drug at skin highly depends on $\mathrm{pH}$. Therefore, the preparations were suitable for application in skin and will easily penetrate through the skin to reach the target site.

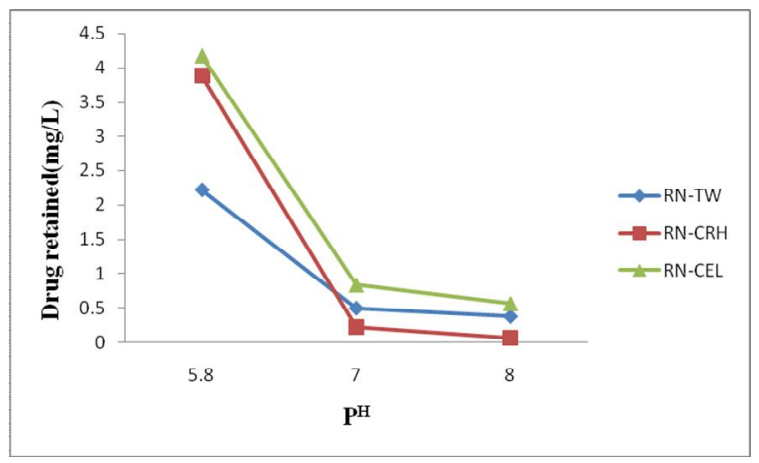

Figure 5. pH stability test for rifampicin nanoemulsions. 
Antibacterial sensitivity test. All rifampicin preparations showed strong antibacterial effect against $S$. epidermidis and $S$. aureus isolated from acne when compared with standard rifampicin (Figure 6). The results of our in vitro studies of this work are encouraging.

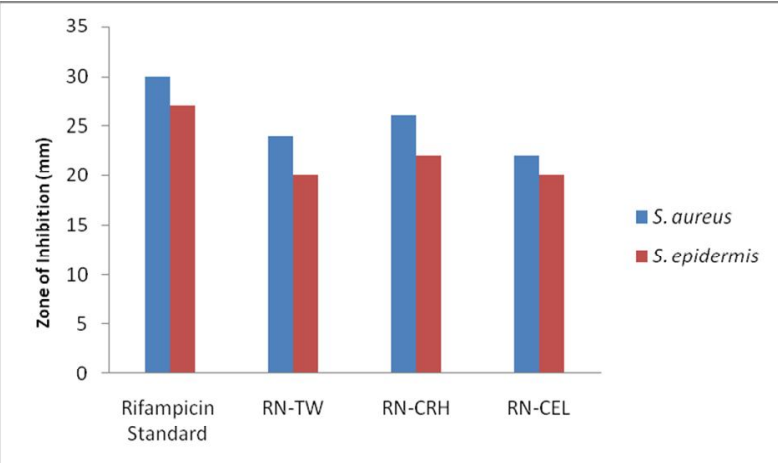

Figure 6. Zone of inhibition for standard rifampicin and rifampicin nanoemulsions.

\section{CONCLUSION}

Rifampicin nanoemulsion preparations were found to be effective against $S$. epidermidis and $S$. aureus isolated from acne. Our study suggests that the rifampicin nanoemulsion formulation has a greater potential in acne. The formulations have shown satisfactory results of particle size, entrapment efficiency, in vitro drug release and $\mathrm{pH}$ stability. This study revealed that nanoemulsion preparetions provide consistent and prolonged release of rifampicin. However, extensive research is required for optimizing its future applications.

\section{REFERENCES}

1. Porras., M, Solans, C., Gonzalez, C., Martinez, A., Guinart, A. and Gutierrez, J.M. 2004. Studies of formation of w/o nanoemulsions. Col. Surf. A 249,115-118.

2. Constantinides, P.P. 1995. Lipid microemulsions for improving drug dissolution and oral absorption and biopharmaceutical aspects. Pharm. Res.12, 1561-1572.

3. Shaji, J., Joshi, V. 2005. Self-microemulsifying drug delivery system (SMEDDS) for improving bioavailability of hydrophobic drugs and its potential to give sustained release dosage forms. Indian J. Pharm. Educ. 39,130-135.
4. Tenjarla, S.N. 1999. Microemulsions: An overview and pharmaceutical applications. Critical Reviews TM in Therapeutic Drug Carrier Systems 16, 461-521.

5. Kreilgaard, M., Pedersen, E.J. and Jaroszewski, J.W. 2000. NMR characterization and transdermal drug delivery potential of microemulsion systems. J. Control. Rel. 69, 421433.

6. Gollnick, H., Cunliffe, W., Berson, D., Dreno, B., Finlay, A., Leyden, J.J., Shalita, A.R. and Thiboutut, D. 2003. Management of acne: a report from a global alliance to improve outcomes in acne. J. Am. Acad. Dermatol. 49, 1-37.

7. Ktistis, G. and Niopas, I. 1998. A study on the in-vitro percutaneous absorption of propranolol from disperse systems. J. Pharm. Pharmacol. 50, 413-418.

8. Dreno, B. and Poli, F. 2003. Epidemiology of acne. Dermatol. 206, 7-10.

9. Hassanzadeh, P., Bahmani, M. and Mehrabani, D. 2008. Bacterial Resistance to antibiotics in acne vulgaris: An in vitro study. Indian J. Dermatol. 53, 122-124

10. White, G.M. 1998. Recent findings in the epidemiologic evidence, classification, and subtypes of acne vulgaris. J. Am. Acad. Dermatol. 39, S34-S37.

11. Silverberg, N.B. and Weinberg, J.M. 2001. Rosaceae and adult acne: a worldwide epidemic. Cutis. $\mathbf{6 8}, 85$.

12. Hiramatsu, J., Kataoka, M. and Nakata, Y. 2003. Propionibacterium acne DNA detected in chroncho alveolar lavage cells from patients with sarcoidosis. J. Sarcoid. Vascu. Diffuse. Lung. Dis. 20, 197-203.

13. Farrar, M. 2007. Genome Sequence and analysis of a propionibacterium acne. J. Bacteriol. 189, 416-417.

14. Ashkenazi, H., Malik, Z., Harth, Y., Nitzan, Y. 2003. Eradication of propionibacterium acnes by its endogenic porphyrins after illumination with high intensity blue light. FEMS Immunol. Med. Microbiol. 35, 17-24.

15. Cunliffe, W.J., Baron, S.E. and Coulson, I.H. 2001. A clinical and therapeutic study of 29 patients with infantile acne. Br. J. Dermatol. 145, 463-466.

16. Tan, H.H., Goh, C.L., Yeo, M.G. and Tan, M.L. 2001. Antibiotic sensitivity of propionibacterium acnes isolates from patients with acne vulgaris in a tertiary dermatological referral centre in Singapore. Ann. Acad. Med. Singapore 30, $22-25$.

17. Załuga, E., Giedrys-Kalemba, S. and Hałasa, J. 1996. Bacterial flora of acne lesions in diagnostic material of the Microbiology and Immunology Department, Pomeranian Medical Academy (PAM) in Szczecin. Med. Dosw. Mikrobiol. 48, 55-59.

18. Gadhiya, P., Shukla, S., Modi, D. and Bharadia, P.A. 2012. Review- niosomes in targeted drug delivery. Int. J. Pharm. Res. Scholars. 2, 59-72. 
19. Iyyanuchamy, S.K., BlessyJesube, R. 2013. Entrapment of antibiotics in biosystem by niosomal drug delivery method. $J$. Drug Deliv. Therap. 3, 6-8.

20. Khan, A.F., Hana, H.K., Sheak, J. and Begum, K. 2015. Antibiotic sensitivity of Staphylococcus aureus and Stap. epidermidis isolated from acne patients. Bangladesh Pharm. J. 18, 121-125.

21. Bauer, A.W., Kirby, W.M., Sherris, J.C. and Turck, M. 1966. Antibiotic susceptibility testing by standardized single disk method. Am. J. Clin. Pathol. 45, 31-32.
22. Becher emulsion: Theory and Practice. Second Ed; Reinhold, New York, 1965.

23. Narang, A.S., Delmarre, D. and Gao, D. 2007. Stable drug encapsulation in micelles and microemulsions. Int. J. Pharm. 345, 9-25.

24. Barry, B.W. 2002. Transdermal drug delivery. Pharmaceutics: The Science of Dosage Form Design. (ed. M.E. Aulton.) Edinburgh Churchill Livingstone, pp. 499-533. 